\title{
No standards: medicolegal investigation of deaths
}

\author{
Diane Kelsall MD MEd, Matthew J. Bowes MD
}

$\mathrm{E}$ ach year, about 230000 residents of Canada die. ${ }^{1}$ In unexplained, unexpected or violent deaths, coroners or medical examiners are charged with determining why and how the person died. ${ }^{2}$ However, concerns have been raised about the quality of medicolegal investigation of deaths and the overall integrity of mortality statistics in Canada. ${ }^{1-3}$

Accurate classification of deaths and quality of reporting have important legal implications and widespread public health implications. Data from death certificates are included in provincial and national databases such as the Canadian Vital Statistics Death Database and the Canadian Coroner and Medical Examiner Database. ${ }^{1,4}$ Despite the importance of medicolegal investigation of deaths, there is no accreditation system for coroner or medical examiner offices, no national standards for the investigation or classification of death, no nationally recognized training program or credentialing system for coroners and medical examiners, and no agreement on common outcome measures against which to evaluate performance. Systems vary substantially between jurisdictions, and no study has addressed whether variation affects the quality of reporting deaths.

In Canada, investigation of unexplained or unnatural deaths is a provincial or territorial responsibility. In six provinces, physicians appointed as coroners or medical examiners (forensic pathologists) have the statutory responsibility to investigate suspicious deaths and determine whether an autopsy is required; in some systems, these same physicians perform the autopsies. ${ }^{2}$ In the other jurisdictions, deaths are investigated by a coroner who is not a physician, and whose background varies but may include law enforcement or nursing. The coroner decides whether an autopsy is necessary, and autopsies are performed by a pathologist. Not all jurisdictions require these pathologists to have additional forensic qualifications or training, however. ${ }^{2}$

Depending on the jurisdiction, $7 \%-45 \%$ of deaths are investigated annually and autopsy rates vary widely, ${ }^{1}$ which raises concerns about potential misclassification of deaths. ${ }^{3,5}$ Death certificates provide valuable information on avoidable mortality and can inform public health policy. ${ }^{4}$ Assigning deaths as "undetermined" in cases of drug overdose, for example, because an investigation or autopsy was not done, precludes efforts to prevent future deaths. ${ }^{5}$ There have been high-profile inquiries into miscarriages of justice in Canada due to faulty forensic evidence. ${ }^{2}$ Completion of death certificates varies between jurisdictions, ${ }^{1,3}$ which makes comparison of mortality data difficult. ${ }^{1-3}$

Lack of an overarching national authority for investigation of deaths has contributed to varied provision of services across Canada, similar to the situation in the United States. ${ }^{6}$ Legislation differs between jurisdictions as to the case-selection criteria for investigation of death, ${ }^{1}$ and the qualifications of the person in charge of the investigation and performing the autopsy. ${ }^{2}$
In all systems, the final responsibility for certification of death lies with the coroner or medical examiner, not with the pathologist. The Royal College of Physicians and Surgeons of Canada has recognized forensic pathology as a subspecialty, and pathways exist for physicians wishing to become forensic pathologists. ${ }^{2}$ However, coroners do not have access to nationally recognized training programs and credentials. ${ }^{2}$ We do not propose that coroner systems cannot function well; indeed, it is difficult to imagine another solution in the larger provinces and territories. Collaboration between pathologists and coroners, however, is key to the system's quality, and all components of the system of investigating death must meet a common standard.

Limited resources underpin these problems. Funding per capita varies substantially by jurisdiction, which may affect decision-making around case selection and autopsies. ${ }^{3,6} \mathrm{Hav}-$ ing few qualified personnel is a problem in remote areas.

Chief coroners and chief medical examiners from each province and territory meet annually. Although useful for the exchange of ideas, this forum has no budget or lawful mandate to set and enforce standards. ${ }^{2}$ An overarching authority similar to that in the United Kingdom, ${ }^{7}$ whether newly created or through powers given to an existing body, is required to develop and oversee practice benchmarks, to implement nationally recognized training programs, to design a credentialing system and to put in place an accreditation system for agencies investigating death.

\section{References}

1. Canadian Coroner and Medical Examiner Database: annual report. Cat. no. 82-214-X. Ottawa: Statistics Canada; 2013. Available: www.statcan.gc.ca/pub /82-214-x/2012001/int-eng.htm (accessed 2015 Dec. 14)

2. Pollanen MS, Bowes MJ, VanLaerhoven SL, et al., editors. Forensic science in Canada: a report of multidisciplinary discussion. Available: www.crime-scene-investigator .net/forensic-science-in-canada.pdf (accessed 2015 Dec. 14)

3. Houle J, Guillou-Ouellette C. Coroners' records on suicide mortality in Montréal: limitations and implications in suicide prevention strategies. Chron Dis Inj Can 2014;34:23-9.

4. Maudsley G, Williams EMI. "Inaccuracy" in death certification: Where are we now? J Public Health Med 1996;18:59-66.

5. Davis GG. Complete republication: National Association of Medical Examiner position paper: Recommendations for the investigation, diagnosis, and certification of deaths related to opioid drugs. J Med Toxicol 2014;10:100-6.

6. Committee for the Workshop on the Medicolegal Death Investigation System. Medicolegal death investigation system: workshop summary. Washington (DC) National Acadamies Press; 2003. Available: www.nap.edu/catalog/10792.html (accessed 2016 Jan. 7).

7. Office of the Chief Coroner: Who is the Chief Coroner? London (UK): Courts and Tribunals Judiciary. Available: www.judiciary.gov.uk/related-offices-and-bodies/ office-chief-coroner/ (accessed 2016 Jan. 3).

Competing interests: Matthew Bowes is Chief Medical Examiner, Nova Scotia. For Diane Kelsall, see www.cmaj.ca/site/misc/cmaj_staff.xhtml.

Affiliations: Deputy Editor (Kelsall), CMAJ; Department of Justice (Bowes), Government of Nova Scotia, Halifax, NS

Correspondence to: $C M A J$ editor, pubs@cmaj.ca

CMAJ 2016. DOI:10.1503/cmaj.160041 